\title{
Management of Earlobe Keloids in Lokoja, Nigeria: A review of twelve cases.
}

\author{
Dr. Stephen Agbomhekhe Ogah (MB.BS \& FMCORL) \\ Consultant Otolaryngologist, Head and Neck Surgeon, O.R.L Division, Department of Surgery, Federal \\ Medical Centre, P.O. Box 1256 Lokoja, Nigeria
}

\begin{abstract}
:
Background: The management of earlobe keloids need to be well highlighted especially among young ladies of African descent as cosmesis is almost always an issue. More so, that there is no clearly defined universally accepted management protocol among medical practitioners. Recurrence is high even after an arduous treatment, follow up visits are mandatory and so patience is required. Choice of treatment depends on the site, size, duration and depth of the lesion. Surgical excision, low-tension wound closure, intra operative corticosteroid injections and pressure wound dressing will give a good cosmetic outcome. Despite all of these, the patient needed to be adequately counseled about recurrence and follow up visits.

Materials and Method: Seven patients with earlobe keloids, 2 unilateral and 5 bilaterally involvement, making a total of twelve earlobe keloids. They were one male and six females, that were treated with surgical excision, low-tension wound closure, intra-operative corticosteroid injections, pressure wound dressing and six weeks of post operative corticosteroids injections. In all patients, a follow-up period of 6 months was the minimum duration.

Results: Male to female ratio was 1: 6, mean age was 28.1years. Ten of the earlobe keloids (83.3\%) resulted from ear piercing and with recurrence in one of the ears $(8.3 \%)$.

Conclusion

Although the sample size is small, follow up period short, surgical excision with adjuvant corticosteroids offers a good outcome. I recommend that Surgeons should stick to treatment that give them best results in their areas of practice with the hope that continued research may one day lead to a better standard of managing these lesions.
\end{abstract}

Key words: Management, Earlobe, Keloids, Lokoja, Nigeria

\section{Introduction}

Keloids are benign skin lesions arising from exuberant proliferation of collagen substance during the healing phase of wound. ${ }^{1}$ In 1806, Alibert was said to have used the term keloid, meaning "crab claw," to described the way the lesions expand laterally from the original scar into normal tissue. ${ }^{2}$ Earlobe keloids usually developed in predisposed individuals at sites of skin injury or as a result of surgical procedures or earlobe piercing or burns. Keloids at presentation appear as smooth, globular, shinning swellings having the same colour as that of the surrounding skin and may occur in one or both ears. Besides cosmetic complaints, others include pain, numbness and itching..$^{3-5}$ These nodular skin lesions may appear like neoplasms and capable of causing much physical disfigurement that borders on the patient's cosmetic and psychological trauma ${ }^{6}$. Whereas keloids grow beyond the original borders of the wound, hypertrophic scars do not extend beyond the original borders of the wound or injury ${ }^{7}$ as shown in figures $1 \& 2$. The hypertrophic scar may regress with time but the keloids will not regress irrespective of time interval given to it to do so. ${ }^{8}$ Hypertrophic scars and keloids are commoner in young Blacks, Hispanics and the Orientals. ${ }^{9}$ Common sites include the shoulders, sternum, earlobes, cheeks and upper arms in susceptible individuals. Predisposing factors may include ear piercing commonly for earrings, surgical wounds, burns and any other form of trauma. ${ }^{10}$ 


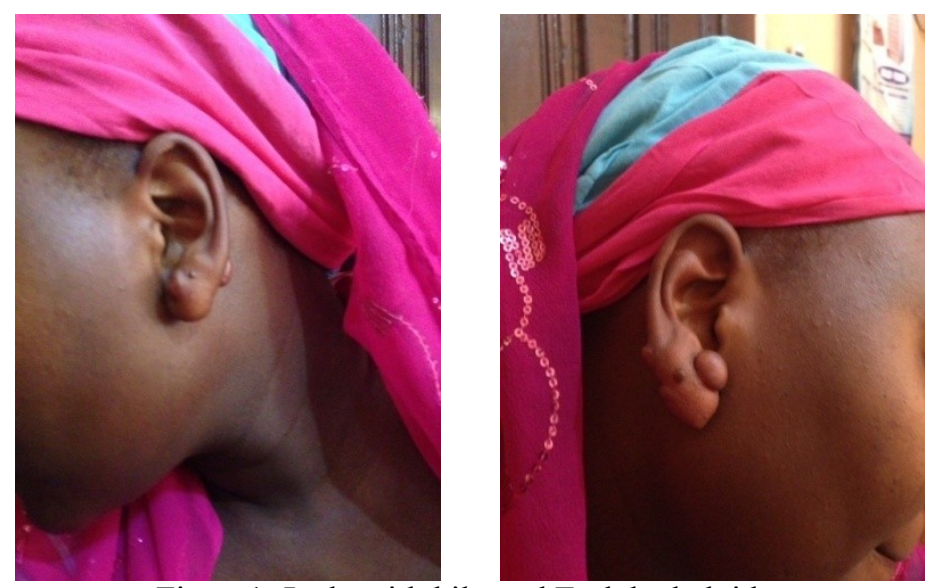

Figure1: Lady with bilateral Earlobe keloids.

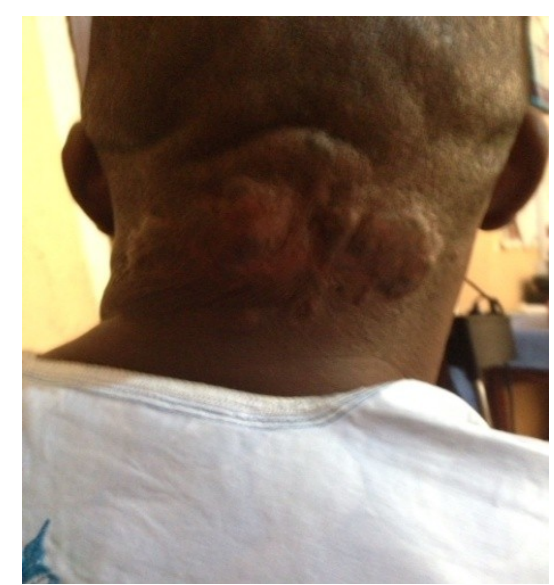

Figure 2: Man with hypertrophic scar from barbing the hair.

\section{Patients and Method}

Twelve ears with earlobe keloids were treated with surgical excision, low-tension wound closure, intra operative corticosteroid injections, pressure wound dressing and six weeks of post operative corticosteroid injections. In all patients, a follow-up period of 6 months was the minimum required.

\section{Results}

One male and six females were involved in the study, with a male to female ratio of 1: 6 . The mean age was 28.1 years. Ten of the earlobe keloids $(83.3 \%)$ resulted from ear piercing and the other two were due minor trauma to the ears. A recurrence in one of the ears $(8.3 \%)$ occurred within the follow up period.

\section{Discussion}

It is often said that prevention is better than cure, so it is with hypertrophic scars and keloids. Whenever possible, they should be prevented because treatment is difficult with a high incidence of recurrence. In dark skinned people, it is important to ask deliberately for a family history of keloid formation. If the patient's family history is positive for keloid formation, such a person should be discouraged from ear piercing and if he or she must pierce the ear, advice to wear a pressure earring should be given. Surgical incisions in such patients should follow Langer's lines whenever possible, none tension suturing with tapes application may help reduce hypertrophic scars and keloids formation. In a study by Asilian et al found that the use of steroids in combination with 5-fluorouracil and pulsed-dye laser reduced hypertrophic scars and keloids formation. ${ }^{11}$ In a prospective study of 121 keloid patients, managed in two teaching hospitals in Nigeria by Olaitan et $\mathrm{al}^{12}$ found out that the symptoms associated with keloids include cosmesis $100.0 \%$, itching $28.9 \%$, pain $26.4 \%$, burning sensation $19.3 \%$ and foul smell $3.3 \%$ respectively.

The primary therapy of earlobe keloids is surgical excision with corticosteroids injections, pressure dressing, and follow-up. ${ }^{13}$ Other adjuvant therapies include the use of silicone cream occlusive dressing, pressure garments, onion extract, bleoyomycin tattooing, mitomycin $\mathrm{C}$, tamoxefin citrate, methotrexate, imiquimod/resiquimod, retinoids with or without steroid combination, botulinum toxin A, vascular endothelial growth factor inhibitor etc. ${ }^{14}$ The use of interleukin-10 and calcineurin are still under clinical trials. ${ }^{15}$ 


\section{References}

[1]. Kelly PA. Medical and Surgical Therapies for keloids. Dermatologic Therapy. 2004; 17:212-218.

[2]. Alibert JLM. Quelques recherches sur la cheloide. Mem Soc Med d'Emul. 1817; 744.

[3]. [Leventhal D, Furr M, Reiter D. Treatment of keloids and hypertrophic scars. Arch Facial Plast Surg. 2006; 8(6):362-368.

[4]. Butler PD, Longaker MT, Yang GP. Current progress in keloid research and treatment. J Am Coll Surg. 2008 ; 206 (4):731-741.

[5]. Berman B, Perez OA, Konda S, et al. A review of the biologic effects, clinical efficacy, and safety of silicone elastomer sheeting for hypertrophic and keloid scar treatment and management. Dermatol Surg. 2007; 33 (11):1291-1303.

[6]. Bock O, Schmid-Ott G, Malewski P, Mrowietz U.Quality of life of patients with keloid and hypertrophic scarring. Arch Dermatol Res.2006, 297:433-8

[7]. Atiyeh BS, Costagliola M, Hayek SN. Keloid or hypertrophic scar: the controversy: review of the literature. Ann Plast Surg. Jun 2005;54(6):676-80..

[8]. Bayat A, Arscott G, Ollier WE, Ferguson MW, Grouther DA. Description of site-specific morphology of keloid phenotypes in an Afrocaribbean population. The British Association of Plastic Surgeons. 2004, 57: 122-133.

[9]. Meenakshi J.V., Ramakrishnan KM Babu M. Keloids and hypertrophic scars: a review. Indian J Plast Surg. 2005;38.:175-179

[10]. Fette A. Influence of silicone on abnormal scarring. Plast Surg Nurs. 2006, 26(2):87-92.

[11]. Lane JE, Waller JL, and Davis LS. Relationship between Age of Ear Piercing and Keloid Formation. Pediatrics. 2005, 115(5):13121314 .

[12]. Asilian A, Daroughheh A, Shariati F. New combination of triamcinolone, 5-fluorouracil, and pulsed-dye laser for treatment of keloid and hypertrophic scars. Dermatol Surg. 2006; 32(7):907-915.

[13]. Olaitan PB, Olabanji JK, Oladele AO, Oseni GA. Symptomatology of keloids in Africans. Sierra Leone Journal of Biomedical Research. 2013 June; 5(1):29-33.

[14]. Shons AR, Press BH. The treatment of earlobe keloids by surgical excision and postoperative triamcinolone injection. Ann Plast Surg. Jun 1983;10(6):480-2

[15]. O'Brien L, Pandit A. Silicon gel sheeting for preventing and treating hypertrophic and keloid scars. Cochrane Database Syst Rev. 2006; (1):CD003826

[16]. Peranteau WH, Zhang L, Muvarak N, et al. IL-10 overexpression decreases inflammatory mediators and promotes regenerative healing in an adult model of scar formation. J Invest Dermatol. 2008;128(7):1852-1860 